\title{
TRAIL receptor I (DR4) polymorphisms C626G and A683C are associated with an increased risk for hepatocellular carcinoma (HCC) in HCV-infected patients
}

Christian Körner ${ }^{1}$, Katarina Riesner ${ }^{1}$, Benjamin Krämer $^{1}$, Marianne Eisenhardt ${ }^{1}$, Andreas Glässner ${ }^{1}$, Franziska Wolter ${ }^{1}$, Thomas Berg², Tobias Müller ${ }^{3}$, Tilman Sauerbruch', Jacob Nattermann', Ulrich Spengler ${ }^{1}$ and Hans Dieter Nischalke ${ }^{1 *}$

\begin{abstract}
Background: Tumour surveillance via induction of TRAIL-mediated apoptosis is a key mechanism, how the immune system prevents malignancy. To determine if gene variants in the TRAIL receptor I (DR4) gene affect the risk of hepatitis C virus (HCV)-induced liver cancer (HCC), we analysed DR4 mutations C626G (rs20575) and A683C (rs20576) in HCV-infected patients with and without HCC.

Methods: Frequencies of DR4 gene polymorphisms were determined by LightSNiP assays in 159 and 234 HCVinfected patients with HCC and without HCC, respectively. 359 healthy controls served as reference population.

Results: Distribution of C626G and A683C genotypes were not significantly different between healthy controls and HCV-positive patients without HCC. DR4 variants 626C and 683A occurred at increased frequencies in patients with HCC. The risk of HCC was linked to carriage of the 626C allele and the homozygous 683AA genotype, and the simultaneous presence of the two risk variants was confirmed as independent HCC risk factor by Cox regression analysis (Odds ratio 1.975, 95\% Cl 1.205-3.236; $\mathrm{p}=0.007$ ). Furthermore HCV viral loads were significantly increased in patients who simultaneously carried both genetic risk factors $\left(2.69 \pm 0.36 \times 10^{6} \mathrm{IU} / \mathrm{ml}\right.$ vs. $1.81 \pm 0.23 \times 10^{6} \mathrm{IU} /$ $\mathrm{ml}, \mathrm{p}=0.049$ ).
\end{abstract}

Conclusions: The increased prevalence of patients with a 626C allele and the homozygous 683AA genotype in HCV-infected patients with HCC suggests that these genetic variants are a risk factor for HCC in chronic hepatitis C.

Keywords: TRAIL receptor I, DR4, Apoptosis, Polymorphism, C626G (rs20575), A683C (rs20576), HCV, HCC, Cancer

\section{Background}

Nearly $3 \%$ of the world population, app. 180 million people, suffer from hepatitis $\mathrm{C}$ virus infection ( $\mathrm{HCV}$ ) thus representing a global health problem [1]. In most of the cases exposure to $\mathrm{HCV}$ results in chronic viral persistence. Progression of chronic hepatitis $\mathrm{C}$ leads to liver fibrosis and cirrhosis and is associated with an increased risk to develop hepatocellular carcinoma (HCC) [2,3]. HCC has become the third leading cause of cancer-related death

\footnotetext{
* Correspondence: nischalke@ukb.uni-bonn.de

'Department of Internal Medicine I, University of Bonn, Sigmund-Freud-Str. 25, 53127 Bonn, Germany

Full list of author information is available at the end of the article
}

worldwide [4-6], and in Western Countries chronic hepatitis accounts for the majority of HCCs. HCV proteins can interact with tumour suppressor proteins as well as with proteins involved in cell-cycle control, and these interactions may promote the development of abnormal cells in the liver.

Tumour development is normally prevented by the immune system, which eliminates transformed cells via induction of apoptosis by tumour necrosis factor-related apoptosis-inducing ligand (TRAIL) [7,8]. Binding of TRAIL to its cognate death receptors DR4 and DR5 triggers activation of the apoptotic cascade, formation of apoptotic bodies and eventually to depletion of the

\section{Biomed Central}


apoptotic cell. DR4 and DR5 are members of the tumour necrosis factor super family and are characterized by the existence of an extra-cellular cysteine-rich binding domain as well as an intra-cellular death domain essential for the transmission of the apoptotic stimulus.

Genetic alterations in death receptors might compromise apoptotic cell signalling and therefore contribute to the development of tumour cells. Several studies suggested an increased risk for cancer associated with single nucleotide polymorphisms (SNPs) in the DR4 gene [9-13]. However, the potential influence of $D R 4$ gene mutations on the development of HCC has not been investigated so far. Therefore, we analysed the effect of the DR4 polymorphisms C626G (Thr209Arg, rs20575) and A638C (Glu228Ala, rs20576) on the occurrence of $\mathrm{HCC}$ in patients chronically infected with $\mathrm{HCV}$.

\section{Methods}

\section{Design and study population}

A total of 393 patients with chronic hepatitis $C$ virus genotype 1 infection from the Bonn and Berlin University Departments of Gastroenterology were enrolled into this study including 159 patients with $\mathrm{HCV}$-associated HCC and 234 patients without HCC. In addition $359 \mathrm{HCV}$ negative healthy individuals and 56 patients with HCC caused by chronic hepatitis B served as control groups. All subjects in this study were of Caucasian descent. Further clinical and demographic characteristics are listed in Table 1.

Cirrhosis was diagnosed either by liver biopsy, transient elastography (stiffness $>15 \mathrm{kPa}$ ), and signs of portal hypertension (splenomegaly, esophageal varices, ascites). The diagnosis of HCC was made by contrast enhanced magnetic resonance imaging and computed tomography according to recently established diagnostic criteria [EASL 2009 and AASLD 2010 guidelines].

Informed consent was obtained from all patients. The study conformed to the ethical guidelines of the Helsinki declaration and had been approved by the University of Bonn ethics committee (reference number: 019/07).

\section{Diagnosis of HCV Infection}

$\mathrm{HCV}$ antibodies were detected with a micro particle enzyme immunoassay (Axsym; Abbott) and confirmed by dot immunoassay (Matrix; Abbott). HCV RNA was detected with a nucleic acid purification kit (QIAamp Viral Kit; Qiagen, Hilden, Germany), followed by reverse transcription and nested polymerase chain reaction. Quantitative determination of $\mathrm{HCV}$ loads was done by branched DNA technology (Chiron, Emeryville, CA). $\mathrm{HCV}$ genotype was determined by the Innolipa II line probe assay (Innogenetics, Zwijndrecht, Belgium).

\section{DR4 Genotyping}

Genomic DNA was extracted from $200 \mu$ l EDTA-blood using the QIAamp Blood Mini Kit (Qiagen, Hilden, Germany) according to the manufacturer's protocol. Determination of the DR4 gene polymorphisms C626G (rs20575) and A683C (rs20576) were performed by LightCycler real time PCR (Roche, Mannheim, Germany) using commercial LightSNiP (SimpleProbe) assays from TIBMolBiol (Berlin, Germany) according to the manufacturer's recommendations.

\section{Statistical analysis}

Genotype frequencies were determined and tested for consistency with Hardy-Weinberg equilibrium using an exact test. Allele and genotype frequencies were compared between cases and controls by Pearson's goodness-of-fit $\left(\chi^{2}\right)$ test and Armitage's trend test, respectively (http:// ihg2.helmholtz-muenchen.de/cgi-bin/hw/hwa1.pl).

Statistical analysis was performed with SPSS 18.0 (SPSS, Munich, Germany). Data are given as means \pm SD, unless stated otherwise. Differences between groups were analyzed by t-test and Mann-Whitney- $U$ test as appropriate.

To take into account potentially confounding risk factors of cirrhosis (age, gender, HBV infection, alcohol and obesity), univariate comparisons (ANOVA and chi2-statistics) followed by forward conditional logistic regression were performed. Parameters with univariate effects at $p<0.1$ were entered into the multivariate analysis with $p<0.05$ for inclusion and $p>0.1$ for exclusion as selection criterion for parameters in the final statistical model.

\section{Results}

The distribution of DR4 C626 > G and A683 > C genetic variants matched the Hardy-Weinberg equilibrium in all analysed groups and subgroups. HCVinfected patients without $\mathrm{HCC}$ revealed a slightly higher allele frequency of the DR4 626C allele (47.2\%) - corresponding to an increased prevalence of $626 \mathrm{C}$ carriers $(70.4 \%)$ - than our healthy controls (allele frequency $41.5 \%$; frequency of $626 \mathrm{C}$ carriers $65.3 \%$; Figure $1 \mathrm{~A}$ ). These differences within the HCV-infected patient groups were apparently independent from the presence of cirrhosis and did not reach statistically significance.

Prevalence of carriers with a 626C allele (genotypes 626CG and CC) (79.9\%) and 626C allele frequency (52.5\%) were significantly increased in the patients with $\mathrm{HCV}$ associated HCC (Figure 1A). The 626C allele frequency in patients with $\mathrm{HCV}$-associated HCC was significantly different only from that in healthy controls $(\mathrm{OR}=1.556,95 \%$ CI: $1.192-2.031, p=0.001)$.

Importantly, the increased prevalence of carriers with a $626 \mathrm{C}$ allele reached statistical significance both with 
Table 1 Patient characteristics and distribution of DR4 genotypes

\begin{tabular}{|c|c|c|c|c|c|c|}
\hline & $\begin{array}{l}\text { Healthy } \\
\text { controls }\end{array}$ & $\begin{array}{c}\mathrm{HCV}(+) \text { all } \\
\text { without } \mathrm{HCC}\end{array}$ & $\begin{array}{l}\text { HCV }(+) \text { Cirrhosis (-) } \\
\text { Without HCC }\end{array}$ & $\begin{array}{l}\mathrm{HCV}(+) \text { Cirrhosis }(+) \\
\text { without HCC }\end{array}$ & $\begin{array}{l}\text { HCV(+) Cirrhosis } \\
\text { (+) with HCC }\end{array}$ & $\begin{array}{c}\text { HBV(+) } \\
\text { With HCC }\end{array}$ \\
\hline Numbers & 359 & 234 & 159 & 75 & 159 & 56 \\
\hline Median age (range) & $59(35-69)$ & $52(39-63)$ & $46(39-57)$ & $55(49-63)$ & $62(54-70)$ & $60(24-83)$ \\
\hline Male Gender (\%) & 51.4 & 66.2 & 65.2 & 69.7 & 58.6 & 75.0 \\
\hline HCV infection (\%) & - & 100 & 100 & 100 & 100 & 0 \\
\hline HCV genotype 1 (\%) & - & 100 & 100 & 100 & 100 & - \\
\hline HCV viral load $\left(10^{6} \mathrm{IU} / \mathrm{ml}\right)^{\text {a) }}$ & - & $2.04 \pm 0.25$ & $2.10 \pm 0.29$ & $1.86 \pm 0.48$ & $1.88 \pm 0.36$ & - \\
\hline HBV infection (\%) & - & 3.2 & 2.8 & 4.0 & 4.4 & 100 \\
\hline $\mathrm{BMI}>30(\%)$ & - & 17.1 & 15.0 & 21.7 & 26.2 & 21.4 \\
\hline Diabetes (\%) & - & 7.7 & 0.8 & 23.0 & 12.0 & 3.6 \\
\hline rs20575 (C626G) ${ }^{b)}$ & $349(100)$ & $233(100)$ & $159(100)$ & $74(100)$ & $159(100)$ & $56(100)$ \\
\hline $\mathrm{CC}$ & $62(17.8)$ & $56(24.0)$ & $38(23.9)$ & $18(24.3)$ & $40(25.2)$ & $9(16.1)$ \\
\hline CG & $166(47.6)$ & $108(46.4)$ & $74(46.5)$ & $34(45.9)$ & $87(54.7)$ & $30(53.6)$ \\
\hline GG & $121(34.7)$ & 69 (29.6) & 47 (29.6) & $22(29.7)$ & $32(20.1)$ & $17(30.4)$ \\
\hline $\begin{array}{l}\text { Deviation from Hardy- } \\
\text { Weinberg equilibrium }^{c} \text { ) }\end{array}$ & $p=0.74$ & $p=0.29$ & $p=0.43$ & $p=0.49$ & $p=0.27$ & $p=0.59$ \\
\hline rs20576 (A683C) b) & $359(100)$ & $234(100)$ & 159 (100) & $75(100)$ & $159(100)$ & $56(100)$ \\
\hline $\mathrm{CC}$ & $19(5.3)$ & $10(4.3)$ & $6(3.8)$ & $4(5.3)$ & $5(3.1)$ & $1(1.8)$ \\
\hline$A C$ & $125(34.8)$ & $85(36.3)$ & $59(35.0)$ & $26(34.7)$ & $33(21.9)$ & $17(30.4)$ \\
\hline AA & $215(59.9)$ & $139(59.4)$ & $94(59.1)$ & $45(60.0)$ & $121(75.8)$ & $38(67.9)$ \\
\hline $\begin{array}{l}\text { Deviation from Hardy- } \\
\text { Weinberg equilibrium c) }\end{array}$ & $p=0.88$ & $p=0.58$ & $p=0.49$ & $p=1.0$ & $p=0.17$ & $p=1.0$ \\
\hline
\end{tabular}

a) Mean \pm SEM, ${ }^{\text {b) }}$ Number of patients (number/\% of total), ${ }^{\text {c) }}$ Fisher's exact test

respect to healthy controls $(\mathrm{OR}=2.106,95 \% \mathrm{CI}: 1.348$ $3.290, p=0.001)$ and to $\mathrm{HCV}$-infected patients without $\mathrm{HCC}(\mathrm{OR}=1.670,95 \% \mathrm{CI}: 1.034-2.696, p=0.034)$ (Figure 1A).

The distribution of $\mathrm{A} 683>\mathrm{C}$ variants did not differ between healthy controls and $\mathrm{HCV}$-infected patients without $\mathrm{HCC}$ irrespective from the presence of cirrhosis (Table 1). Patients with HCV-associated HCC had the highest frequency of the $623 \mathrm{~A}$ allele $(86.5 \%)$, which was significantly increased as compared to healthy controls (A allele frequency $77.3 \%$, OR $=1.856$ 95\% CI: 1.291 2.667, $p=0.0006)$ and HCV-infected patients without $\mathrm{HCC}$ (A allele frequency $77.6 \%, \mathrm{OR}=1.828,95 \% \mathrm{CI}$ : $1.243-2.686, p=0.002)$. This deviation was strong enough to achieve statistical significance even when HCVinfected subgroups with and without cirrhosis were compared separately (cirrhosis: $77.3 \%$ A allele frequency, $\mathrm{OR}=1.852$, 95\% CI: $1.126-3.045, p=0.013$; without cirrhosis: $77.7 \%$ A allele frequency, OR $=1.816,95 \% \mathrm{CI}$ : 1.201-2.746, $p=0.004$ ).

These changes were due to a significant increase in the proportion of patients with the homozygous 683AA genotype in patients with HCV associated HCC (76.1\%) as compared to healthy controls $(59.9 \%$, OR $=0.477,95 \%$ CI: 0.314-0.725, $p=0.0003)$ and HCV-infected patients without HCC $(59.4 \%, \mathrm{OR}=0.468,95 \% \mathrm{CI}$ : 0.300-0.730, $p=0.0006)$, irrespective whether cirrhosis was present (60.0\%, OR $=0.480,95 \% \mathrm{CI}: 0.267-0.862, p=0.011)$ or not $(59.1 \%, \mathrm{OR}=0.462,95 \% \mathrm{CI}: 0.286-0.747, p=0.001)$ (Figure 1B). Interestingly, HCV viral loads tended to be increased in patients who carried the genetic risk variants associated with polymorphisms C626G $\left(2.44 \pm 0.28 \times 10^{6}\right.$ $\mathrm{IU} / \mathrm{ml}$ vs. $1.85 \pm 0.30 \times 10^{6} \mathrm{IU} / \mathrm{ml}$, n.s. $)$ and A683C (2.30 \pm $0.27 \times 10^{6} \mathrm{IU} / \mathrm{ml}$ vs. $1.94 \pm 0.26 \times 10^{6} \mathrm{IU} / \mathrm{ml}$, n.s. $)$, and this effect reached statistical significance in patients who simultaneously carried both genetic risk factors (2.69 \pm $0.36 \times 10^{6} \mathrm{IU} / \mathrm{ml}$ vs. $\left.1.81 \pm 0.23 \times 10^{6} \mathrm{IU} / \mathrm{ml}, \mathrm{p}=0.049\right)$ (Figure 2).

Next, we checked whether variants in the TRAIL receptor I (DR4) gene were confirmed as independent $\mathrm{HCC}$ risk factors in $\mathrm{HCV}$-infected patients when known risk factors such as age, sex, obesity, diabetes, HCV viral load and HBV co-infection were also taken into account (Table 2). Univariate analysis identified age $(\mathrm{OR}=1.076$ per year, 95\% CI: 1.053-1.098, p < 0.0001), carriage of a $626 \mathrm{C}$ allele (OR $=1.670,95 \% \mathrm{CI}: 1.034-2.696, p=0.035)$, the homozygous 683AA genotype $(\mathrm{OR}=2.176,95 \% \mathrm{CI}$ : $1.390-3.407, p=0.001)$ and the simultaneous presence of both genetic variants $(\mathrm{OR}=1.940,95 \% \mathrm{CI}$ : $1.280-2.940$, $p=0.002$ ) as risk factors of HCC (Table 2). In the multivariate regression analysis age was found to be an independent risk factor for the development of $\mathrm{HCC}$ in chronic hepatitis C (OR $=1.074,95 \%$ CI: 1.052-1.097, $p \leq$ $0.001)$. More importantly, we could confirm that the simultaneous presence of a $626 \mathrm{C}$ allele in combination with the homozygous 683AA genotype was significantly 


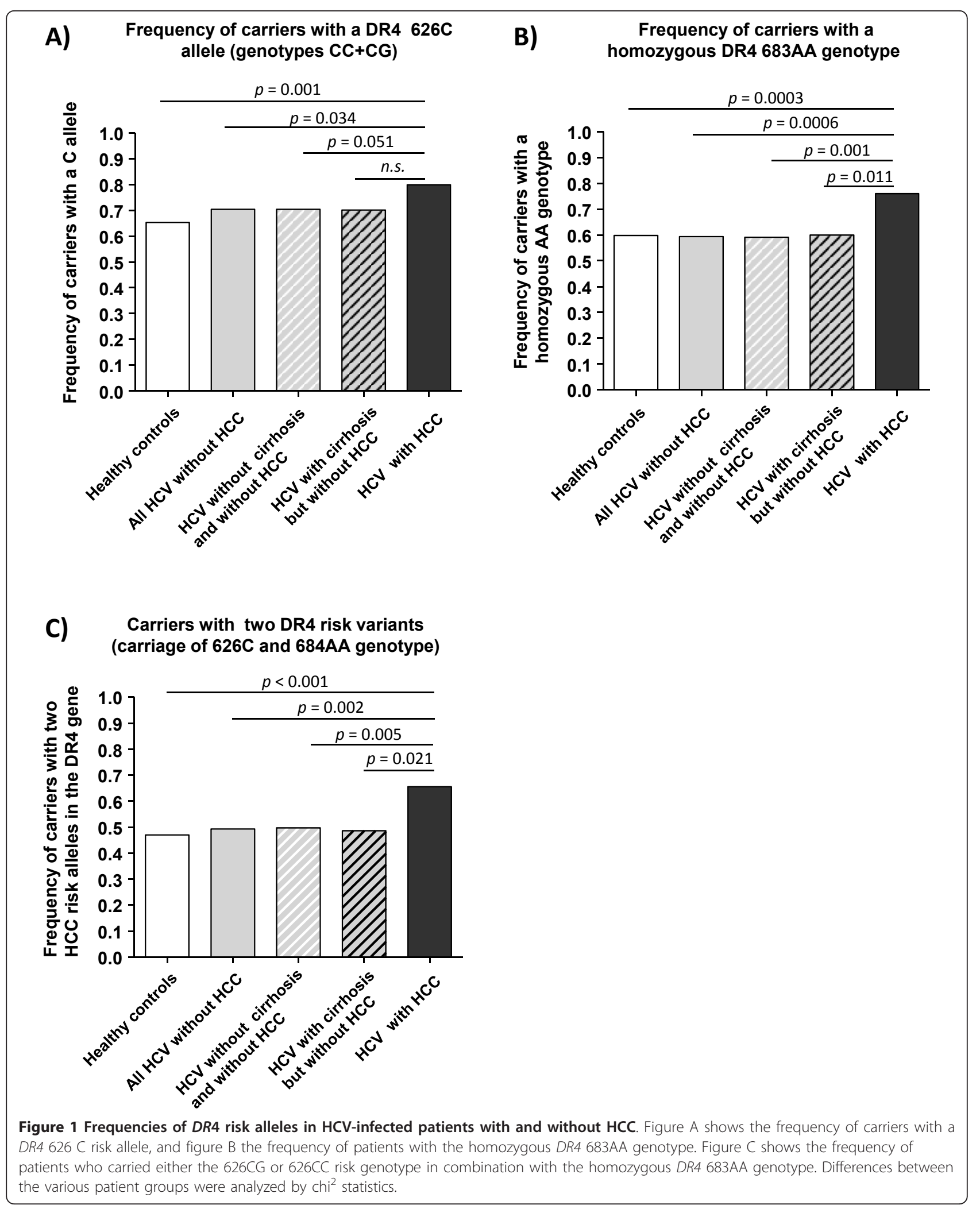




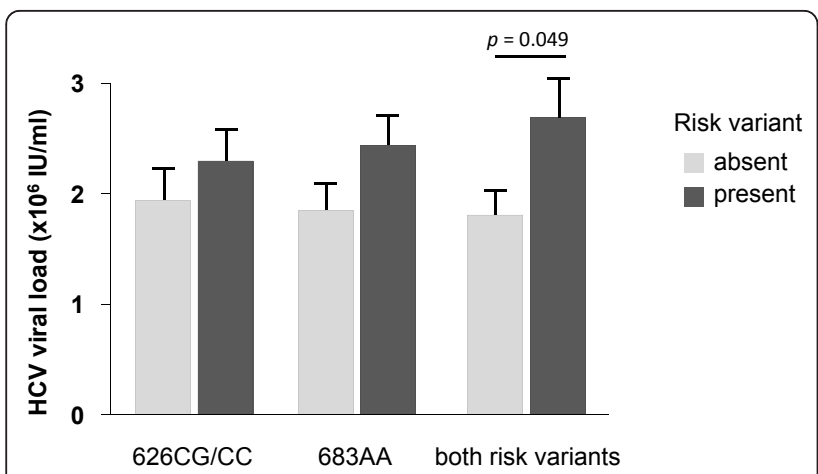

Figure $2 \mathrm{HCV}$ viral loads in patients with and without genetic DR4 risk variants. This Figure shows HCV viral loads (Means \pm SEM) in patients who carry the DR4 626CG or 626CC risk variant (left columns), the DR4 683AA risk variant (middle columns) and both $D R 4$ risk variants simultaneously (right columns). Dark columns refer to patients with the studied risk factor, grey columns to those without the risk factor, respectively. Differences were compared by ANOVA.

associated with the occurrence of $\mathrm{HCC}$ in this continuative analysis (OR $=1.975,95 \% \mathrm{CI}: 1.205-3.236, p=0.007)$ and could therefore identify the combined carriage of a $D R 4$ risk variant as new independent predictor for the development of HCC in chronic hepatitis C.

To check, if our findings were specific for hepatitis $C$, we performed a similar analysis in our group of HCC patients, who had chronic hepatitis B. However, unlike hepatitis $\mathrm{C}$-associated $\mathrm{HCC}$ the distributions of genetic $D R 4$ variants in $\mathrm{HBV}$-associated $\mathrm{HCC}$, healthy controls and $\mathrm{HCV}$-positive patients without $\mathrm{HCC}$ were not significantly different (Table 1 ). In particular, the simultaneous combination of a $626 \mathrm{C}$ allele with the 683AA genotype was observed in rather similar frequencies in the groups with $\mathrm{HBV}$-associated HCC (50.0\%), hepatitis $\mathrm{C}$ without HCC (49.4\%) and healthy controls (47.0\%) while the difference in frequency between $\mathrm{HBV}$-and HCV-associated HCC (65.4\%) was significant $(\mathrm{OR}=$ 1.891, 95\% CI: 1.020-3.506, $p=0.042$ ).

\section{Discussion}

Emerging evidence suggest an important role of TRAIL for control and elimination of HCV infection. TRAIL has been implicated in the death of HCV-infected but not normal liver cells [14]. In HCV infection its expression on natural killer cells is up-regulated by interferon, and is inversely correlated to HCV-RNA serum levels $[15,16]$. TRAIL can also induce cell death in hepatic tumour cells but expression of TRAIL receptors on human hepatocellular carcinoma is variable and frequently down-regulated [17]. Nevertheless, several studies suggest TRAIL receptor-mediated apoptosis to play a role in the elimination of tumour cells in human hepatocellular carcinoma $[18,19]$.

In this study we found that the TRAIL receptor I wild type with threonine at amino acid position 209 (626C) and alanine at position 228 (638A) is associated with an increased risk of $\mathrm{HCC}$ in patients with chronic hepatitis C. Of note, it was particularly the combination of the risk genotypes $626 \mathrm{CC}$ or $626 \mathrm{CG}$ with the homozygous 683AA genotype that was identified as a new independent predictor for HCC. Interestingly, this association of DR4 genetic variants and the risk to develop $\mathrm{HCC}$ was evident only for patients with chronic hepatitis $C$ but not hepatitis B, suggesting a critical role of the aetiology underlying HCC. Both polymorphisms in the DR4 gene have already been reported to affect the risk for other

Table 2 Regression analysis for risk factors of HCC among patients with hepatitis C genotype 1

\begin{tabular}{|c|c|c|c|c|}
\hline \multirow[b]{3}{*}{ Parameter } & \multicolumn{2}{|c|}{ Univariate analysis } & & \\
\hline & & \multicolumn{3}{|c|}{$95 \%$ Confidence interval } \\
\hline & $p$-value & Odds ratio & Lower & Upper \\
\hline Age $^{\S}$ & 0.000 & 1.076 & 1.053 & 1.098 \\
\hline Diabetes mellitus & 0.369 & 1.412 & 0.691 & 2.886 \\
\hline Gender (male) & 0.135 & 1.430 & 0.915 & 2.236 \\
\hline HBV infection & 0.626 & 1.295 & 0.460 & 3.646 \\
\hline HCV viral load $\left(10^{6} \mathrm{IU} / \mathrm{ml}\right)$ & 0.339 & 0.960 & 0.883 & 1.044 \\
\hline Obesity $(\mathrm{BMI}>30)$ & 0.153 & 1.668 & 0.867 & 3.211 \\
\hline C626G genotype ([CC+CG] vs. GG) & 0.035 & 1.670 & 1.034 & 2.696 \\
\hline A683C genotype (AA vs. $[A C+C C]$ ) & 0.001 & 2.176 & 1.390 & 3.407 \\
\hline \multirow[t]{3}{*}{ Combined $626 \mathrm{C}$ and $683 \mathrm{AA}$ risk genotype vs. all other combinations } & 0.002 & 1.940 & 1.280 & 2.940 \\
\hline & \multicolumn{2}{|c|}{ Multivariate analysis* } & & \\
\hline & & & \multicolumn{2}{|c|}{ 95\% Confidence interval } \\
\hline Parameter & p-value & Odds ratio & Lower & Upper \\
\hline Age $\S$ & 0.000 & 1.074 & 1.052 & 1.097 \\
\hline Combined $626 \mathrm{C}$ and $683 \mathrm{AA}$ risk genotype & 0.007 & 1.975 & 1.205 & 3.236 \\
\hline
\end{tabular}

\footnotetext{
* including all significant parameters from univariate analysis, ${ }^{\S} \mathrm{OR}(95 \% \mathrm{Cl})$ per year
} 
types of malignancy. However, in a previous study investigating the role of the $D R 4 \mathrm{~A} 683 \mathrm{C}$ polymorphism in chronic lymphocytic leukaemia, mantle cell lymphoma, prostate cancer, head and neck squamous cell carcinoma and bladder cancer an increased frequency of the CC genotype was apparently linked to malignancy [20]. In contrast, Frank et al. observed an increased percentage of carriers with the AA genotype in patients with breast cancer [10]. Moreover, they found an increased percentage of carriers of the $626 \mathrm{CC}$ genotype similar to our results. At present, it remains unclear which mechanisms underlie DR4 polymorphisms C626G and A683C to affect the risk for malignancy.

However, both amino acid exchanges are in the extracellular cysteine-rich domain of DR4. Therefore both genetic variants may lead to alterations in the TRAILbinding domain and thus alter DR4 affinity for TRAIL. Since TRAIL signalling presumably contributes importantly to the control of HCV infection, our finding of significantly increased HCV viral loads in carriers of both $D R 4$ risk factors suggests that TRAIL-DR4 signalling is less efficient in these patients. In line with this reasoning less efficient signalling of cell death in transformed cells and reduced susceptibility of transformed hepatocytes towards TRAIL-induced apoptosis would also facilitate HCC development. On the other hand, we cannot exclude the possibility that the increased HCC risk in HCV-infected patients carrying the C626G and A683C risk variants of TRAIL receptor I simply reflects less efficient immune control over HCV infection via TRAILmediated mechanisms. TRAIL is likely to affect tumour surveillance of transformed HCV-infected cells by the immune system and viral loads, once HCV infection has occurred [14]. On the other hand our data suggest that neither of the DR4 polymorphisms affects susceptibility to HCV infection. This constellation can be explained by the fact that $D R 4$ expression is rather low on normal liver cells while up-regulated $D R 4$ expression following HCV infection sensitizes liver cells towards TRAILmediated apoptosis [14,21]. Thus, sufficient DR4 expression on transformed liver cells appears to be a pivotal prerequisite for efficient tumour surveillance by the immune system, in line with recent clinical findings [17].

Therefore the role of TRAIL and DR4 polymorphisms should be further studied in patients whose risk for $\mathrm{HCC}$ is attributed to different aetiologies.

\section{Conclusion}

Here, we provide first evidence that $\mathrm{HCV}$ genotype 1 infected carriers of a $D R 4626 \mathrm{C}$ allele in combination with the DR4 683AA genotype have an increased risk for HCC indicating that TRAIL and its receptors contribute importantly to control of HCV infection and tumour surveillance by the immune system. The combined presence of the two DR4 risk variants can help to identify $\mathrm{HCV}$ infected patients with an increased risk for liver cancer, who may need more intensive cancer monitoring.

\section{Acknowledgements}

This work was supported by a grant from the German Federal Ministry of Education and Research (BMBF) within the network for resistance in hepatitis C, grant number (01KI0792) to JN and US. By a grant from the H.W. \& J. Hector foundation, grant number (M42) to JN and by the Deutsche Krebshilfe grant number (107865) to HDN and US.

\section{Author details}

${ }^{1}$ Department of Internal Medicine I, University of Bonn, Sigmund-Freud-Str. 25, 53127 Bonn, Germany. ${ }^{2}$ Department of Gastroenterology, University Hospital Leipzig, Philipp-Rosenthal-Strasse 27, 04103 Leipzig, Germany. ${ }^{3}$ Medical Clinic for Hepatology and Gastroenterology, Medical University Charité, Augustenburger Platz 1, 13353 Berlin, Germany.

\section{Authors' contributions}

KR and FW established and performed the real-time PCRs for DR4 genotyping. BK, ME, TM and TB collected and analyzed clinical data and collected samples from the study population. HDN, US, and JN designed the study and did statistical analysis. CK and TS wrote the manuscript. All authors read and approved the final manuscript.

\section{Competing interests}

The authors declare that they have no competing interests.

Received: 30 August 2011 Accepted: 8 March 2012

Published: 8 March 2012

\section{References}

1. Alter MJ: Epidemiology of hepatitis C. Hepatology 1997, 26(3 Suppl 1):62S-65S.

2. Moradpour D, Blum HE: Pathogenesis of hepatocellular carcinoma. Eur J Gastroenterol Hepatol 2005, 17(5):477-483.

3. Tsukuma H, Hiyama T, Tanaka S, Nakao M, Yabuuchi T, Kitamura T, Nakanishi K, Fujimoto I, Inoue A, Yamazaki H, et al: Risk factors for hepatocellular carcinoma among patients with chronic liver disease. $N$ Engl J Med 1993, 328(25):1797-1801.

4. $\quad$ Altekruse SF, McGlynn KA, Reichman ME: Hepatocellular carcinoma incidence, mortality, and survival trends in the United States from 1975 to 2005. J Clin Oncol 2009, 27(9):1485-1491.

5. Schutte K, Bornschein J, Malfertheiner P: Hepatocellular carcinomaepidemiological trends and risk factors. Dig Dis 2009, 27(2):80-92.

6. Shepard CW, Finelli L, Alter MJ: Global epidemiology of hepatitis C virus infection. Lancet Infect Dis 2005, 5(9):558-567.

7. Mellier G, Huang S, Shenoy K, Pervaiz S: TRAlLing death in cancer. Mol Aspects Med 2010, 31(1):93-112.

8. Yang A, Wilson NS, Ashkenazi A: Proapoptotic DR4 and DR5 signaling in cancer cells: toward clinical translation. Curr Opin Cell Biol 2010, 22(6):837-844.

9. Chen B, Liu S, Wang XL, Xu W, Li Y, Zhao WH, Wu JQ: TRAIL-R1 polymorphisms and cancer susceptibility: an evidence-based metaanalysis. Eur J Cancer 2009, 45(14):2598-2605.

10. Frank B, Hemminki K, Shanmugam KS, Meindl A, Klaes R, Schmutzler RK, Wappenschmidt B, Untch $M$, Bugert $P$, Bartram CR, et al: Association of death receptor 4 haplotype 626 C-683C with an increased breast cancer risk. Carcinogenesis 2005, 26(11):1975-1977.

11. Frank B, Shanmugam KS, Beckmann L, Hemminki K, Brenner $H$, Hoffmeister M, Chang-Claude J, Burwinkel B: Death receptor 4 variants and colorectal cancer risk. Cancer Epidemiol Biomarkers Prev 2006, 15(10):2002-2005.

12. Ulybina $\mathrm{YM}$, Kuligina $\mathrm{E}$, Mitiushkina NV, Rozanov ME, Ivantsov $\mathrm{AO}$, Ponomariova DN, Togo AV, Levchenko EV, Shutkin VA, Brenister SI, et al: Coding polymorphisms in Casp5, Casp8 and DR4 genes may play a role in predisposition to lung cancer. Cancer Lett 2009, 278(2):183-191.

13. Wang $M$, Wang M, Cheng G, Zhang Z, Fu G, Zhang Z: Genetic variants in the death receptor 4 gene contribute to susceptibility to bladder cancer. Mutat Res 2009, 661(1-2):85-92. 
14. Lan L, Gorke S, Rau SJ, Zeisel MB, Hildt E, Himmelsbach K, Carvajal-Yepes M, Huber R, Wakita T, Schmitt-Graeff A, et al: Hepatitis C virus infection sensitizes human hepatocytes to TRAlL-induced apoptosis in a caspase 9-dependent manner. J Immunol 2008, 181(7):4926-4935.

15. Ahlenstiel G, Edlich B, Hogdal L, Rotman Y, Noureddin M, Feld JJ, Holz LE, Titerence RH, Liang TJ, Rehermann B: Early Changes in Natural Killer Cell Function Indicate Virologic Response to Interferon Therapy for Hepatitis C. Gastroenterology 2011, 141(4):1231-1239.

16. Stegmann KA, Bjorkstrom NK, Veber $\mathrm{H}$, Ciesek $\mathrm{S}$, Riese $\mathrm{P}$, Wiegand J, Hadem J, Suneetha PV, Jaroszewicz J, Wang C, et al: Interferon-alphainduced TRAIL on natural killer cells is associated with control of hepatitis C virus infection. Gastroenterology 2010, 138(5):1885-1897.

17. Kriegl L, Jung A, Engel J, Jackstadt R, Gerbes AL, Gallmeier E, Reiche JA, Hermeking H, Rizzani A, Bruns CJ, et al: Expression, cellular distribution, and prognostic relevance of TRAIL receptors in hepatocellular carcinoma. Clin Cancer Res 2010, 16(22):5529-5538.

18. Chen XP, He SQ, Wang HP, Zhao YZ, Zhang WG: Expression of TNF-related apoptosis-inducing Ligand receptors and antitumor tumor effects of TNF-related apoptosis-inducing Ligand in human hepatocellular carcinoma. World J Gastroenterol 2003, 9(11):2433-2440.

19. He S, Chen Y, Chen X, Zhao Y, Wang H, Zhang W, Wang S: Antitumor effects of soluble TRAIL in human hepatocellular carcinoma. J Huazhong Univ Sci Technolog Med Sci 2005, 25(1):51-54.

20. Wolf S, Mertens D, Pscherer A, Schroeter P, Winkler D, Grone HJ, Hofele C, Hemminki K, Kumar R, Steineck G, et al: Ala228 variant of trail receptor 1 affecting the ligand binding site is associated with chronic lymphocytic leukemia, mantle cell lymphoma, prostate cancer, head and neck squamous cell carcinoma and bladder cancer. Int J Cancer 2006, 118(7):1831-1835.

21. Zhu H, Dong H, Eksioglu E, Hemming A, Cao M, Crawford JM, Nelson DR, Liu C: Hepatitis C virus triggers apoptosis of a newly developed hepatoma cell line through antiviral defense system. Gastroenterology 2007, 133(5):1649-1659.

\section{Pre-publication history}

The pre-publication history for this paper can be accessed here: http://www.biomedcentral.com/1471-2407/12/85/prepub

doi:10.1186/1471-2407-12-85

Cite this article as: Körner et al:: TRAIL receptor I (DR4) polymorphisms C626G and A683C are associated with an increased risk for hepatocellular carcinoma (HCC) in HCV-infected patients. BMC Cancer 2012 12:85

\section{Submit your next manuscript to BioMed Central and take full advantage of:}

- Convenient online submission

- Thorough peer review

- No space constraints or color figure charges

- Immediate publication on acceptance

- Inclusion in PubMed, CAS, Scopus and Google Scholar

- Research which is freely available for redistribution

Submit your manuscript at www.biomedcentral.com/submit
Biomed Central 